\title{
Net-Zero Emissions With Renewable Energy Certificates: A Public Policy for a Massachusetts Municipal Light Plant
}

\author{
Joseph Yaw Abodakpi ${ }^{1}$, Patrick Collins ${ }^{2} \&$ Aidan Giasson $^{2}$ \\ ${ }^{1}$ Department of Financial Policy, Cracow University of Economics, Cracow, Poland \\ ${ }^{2}$ School of Professional Studies, Clark University, Worcester, USA \\ Correspondence: Joseph Yaw Abodakpi, Department of Financial Policy, Cracow University of Economics, Cracow, \\ Poland. E-mail: joseph.abodakpi@uek.krakow.pl
}

Received: August 7, 2021

Accepted: September 7, 2021

Online Published: October 12, 2021

doi:10.5430/ijfr.v12n5p180

URL: https://doi.org/10.5430/ijfr.v12n5p180

\begin{abstract}
The promotion, desire and need for renewable energy generation and transmission to electric grids to provide clean, non-carbon-based power has increased in recent years with more focus on climate change mitigation in both the public and private sectors. Renewable Energy Certificates, also known as "RECs" are the established public policy mechanism for incentivizing, verifying, tracking and supporting renewable energy. REC markets are created and managed by state governments to allow selling, purchasing and trading of these "green commodities" to substantiate environmental attribute claims. A new legislation in Massachusetts requires all stakeholders, businesses and sectors to reduce emissions, which means electric utilities, both public and private, must participate in REC markets to green their power supply portfolios that they provide to consumers. This paper explores and analyzes the role of REC markets, monetary policy, trends, stakeholders, participants, and the current public policy debates in this area. A specific public policy making case is explored for this research, the Municipal Light Plant in Shrewsbury, MA, utilizing RECs to achieve a $100 \%$ non-carbon power supply or "net-zero" emissions. A financial analysis based on REC market research and debate is conducted to inform a rules-based and judgement-based fiscal Power Supply Policy and Greenhouse Gas Emissions Standard for SELCO (Shrewsbury Electric and Cable Operations), a public electricity utility.
\end{abstract}

Keywords: Renewable Energy Certificates (RECs), net-zero emissions, non-carbon electricity, greenhouse gas emissions standard, power supply policy, municipal light plant (MLP)

\section{Introduction and Background Information}

Renewable energy generation and distribution to end users through the electric grid is an essential action to address climate change. Historically, this has been more expensive compared to traditional fossil fuel energy generation, therefore, governments have stepped in to incentivize renewable energy generation by assigning it monetary value. As the Environmental Protection Agency explains, "because the physical electricity we receive through the utility grid says nothing of its origin or how it was generated, RECs play an important role in accounting, tracking, and assigning ownership to renewable electricity generation and use." (n.d.) In many US states, each megawatt hour (MWh) of electricity generated by a certified renewable resource produces a Renewable Energy Certificate (REC) that has a dollar value. This "green commodity" can be sold, traded, bought and retired to claim ownership or credit of the environmental attributes, in REC markets.

This value that is assigned to renewable energy incentivizes clean, renewable energy development over fossil fuels that emit greenhouse gases. An analogy that can help one understand RECs is to think about it like a house and deed. The house is the electric energy and the deed is the REC, these are two separate components where one can live in the house without owning the deed. When you buy the power generated by a renewable source, but do not purchase and retire the REC, you do not own the right (deed) to claim that as a renewable resource in your power portfolio. Similarly, one can own the deed to a house you don't live in. This is the equivalent to purchasing and retiring RECs to claim the renewable resource. The REC market is a unique form of monetary policy where state governments essentially act as central banks, setting up the foundation market and injecting targeted economic stimulus. The renewable generating sources act as commercial banks, accelerating the effect of the initial influence from the state by providing the REC assets. Electric utilities, large corporations and general consumers utilize these assets by buying them, confirming their 
monetary value. The state can set price ceilings, floors, and inject stimulus with different rules, regulations and public policies. In Massachusetts, the Department of Energy Resources (DOER) is responsible for management and oversight of this market.

Electric utilities are one of the most important participants in REC markets, as they procure electric power from various generating sources and deliver it to consumers through distribution networks. The power supply portfolio of electric utilities vary depending on contracted power purchase agreements (PPAs). Governments have required these portfolios to have a minimum percentage of non-carbon emitting generation. Private, for-profit, investor-owned utility companies like National Grid, have historically been required to have minimum percentages, participating in compliance REC markets. Starting in 2021, Massachusetts public electric utilities, also known as Municipal Light Plants (MLPs) must also meet minimum requirements detailed in the recently passed climate action bill S.9, having "net-zero" emissions by 2050 at the latest, with $100 \%$ non-carbon portfolios. Governments are looking at the electricity sector as the foundation upon which to build completely net-zero communities. The plan is to have the electricity provided to consumers be $100 \%$ carbon free, so that consumers can "fuel shift" their currently fossil fueled assets, like heating/cooling systems, vehicles, and other equipment to electric equipment.

Reliance on the REC market is critical to reaching this goal, as the only way to claim non-carbon power supply credit is with RECs produced by renewable energy generation or emissions free energy certificates (EFECs) produced by nuclear generation. Failure to meet emissions reduction requirements outlined in S.9 will result in utilities having to make Alternative Compliance Payments (ACPs) to the Massachusetts Clean Energy Center (MassCEC), which aids the development of renewable energy projects. The stability, pricing, oversight and management of these markets by state governments will dictate feasibility of accomplishing net-zero emissions through the electricity sector. The future outlook of pricing for REC markets is uncertain, but growth and increase in participation is guaranteed (Heeter, J., \& O'Shaughnessy, 2020). One of the primary objectives of this research paper is to investigate and describe the role, policies, trends and pros/cons of REC markets and green commodities with the scope of studying various REC markets around the world, but the main focus will be US markets, particularly the New England region. Another primary objective is to analyze this information and data to inform a power supply policy for Shrewsbury, Massachusetts' municipal light plant SELCO (Shrewsbury Electric and Cable Operations) that utilizes RECs to achieve net-zero carbon emissions. This has not been conducted extensively for a particular case with an academic approach, therefore this study brings new knowledge to the area of "green finance" and the economics of emissions reduction.

\section{Literature Review}

The role of RECs in engaging communities to lower their dependence on GHG emitting energy sources has seen huge growth in the late 1990s. Government-imposed use of RECs to meet green energy goals has boasted the use and led to an expansion in the green energy market. While investing in green energy has become more stable over time it's still viewed as volatile. This volatility makes investors wary about putting their money towards green energy projects without the reassurance that they will receive a return on their investment. RECs have sprung to larger popularity as state governments begin to mandate their use to lower the dependence on GHG emitting energy sources. The market is focused on electricity, as the grid is set up to allow for energy from all sources. Both voluntary and compliance REC markets have particular features that differentiate themselves from each other (Figure 1).

The main purpose for these differences is due to their target audiences which can be explained as consumers for voluntary markets and distributors for compliance markets. Both markets feature similar issues on different scales with voluntary markets being more stable as the growth in these markets is more natural in opposition to the rise in compliance policies in many states. As seen on Figure 1, there are a lot more actors and stakeholders involved in the voluntary markets in order to protect consumers and give them the best possible prices to encourage participation.

The RECs market growth has been rapid in the past few years and the expansion potential is great as individual states and communities begin to adopt carbon-free electricity timelines. For the energy sector in Massachusetts, RECs have been established as the way the state will reach its goal of reaching net-zero emissions by 2050 . The growth in the market has seen a lean towards utility-market partnerships for residential areas (Holt and Bird, 2005). 


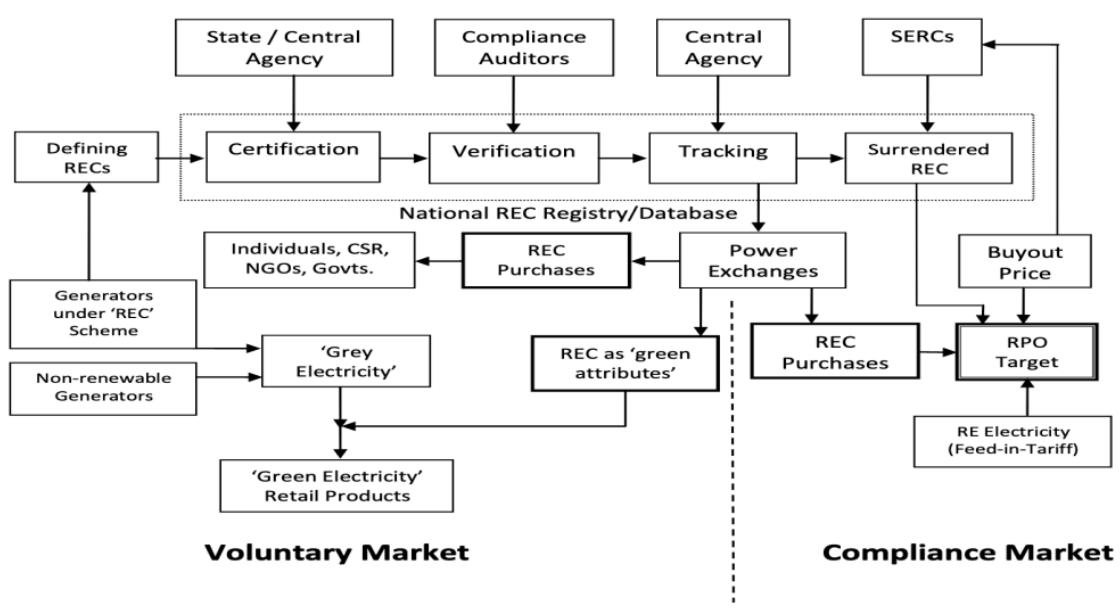

Figure 1. Participants and Actions in REC Markets

Source: Singh, 2011, pg. 3

These partnerships allow consumers to easily access green energy through their provider without having to do research on particular RECs. Data from the U.S. Energy Information administration supports that when energy suppliers offer green products as a standard option that their sales increase more than their competitors that don't have those options (Holt and Bird, 2005). The renewable energy industry is at the center of the REC market. While the REC market stimulates the development of renewable energy production the demand and supply have been unable to line up leading to inconsistent pricing of RECs. This is mainly caused by large upfront costs of building the power generating plants coupled with the past uncertainty of the market's success. Long-term contracts that bundle energy and RECs are utilized in the energy field to mitigate the risk for investors and encourage their financial support (Holt et al, 2011). The development of new projects will be key to maintain the expansion of RECs as the current trajectory shows the gap between supply and demand growing (Holt et al, 2011).

Prices differ between states, REC type, and voluntary and compliance markets (Figures 2 and 3). The voluntary market is for individuals or businesses who purchase RECs to offset carbon emissions created by their activity and operations, while the compliance market consists mostly of electricity companies that purchase large shares to distribute to their customers. Participants in compliance markets must purchase RECs to reach non-carbon energy goals set by the government. RECs in the compliance market are used to track the type of energy sources that electricity companies are using. Even in individual states, pricing can greatly fluctuate with Massachusetts seeing \$15 to \$50 per REC in 2011 (Holt et al, 2011) (Figure 3). Heeter (2020) has claimed that REC pricing correlates with electricity demand, as both are measured in MWhs, but this is likely only somewhat correlated at a generalized national level for unbundled RECs and ERCOT (Texas) electric pricing (Figure 4). 


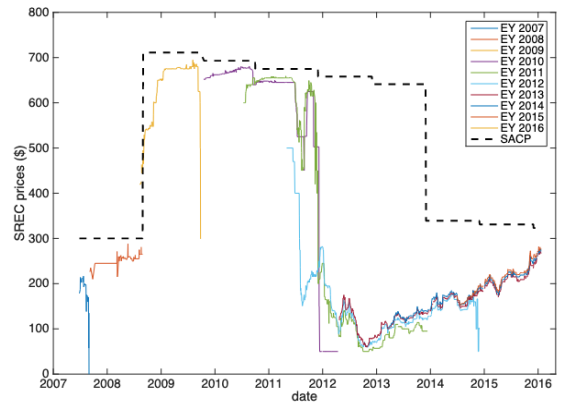

(a) Daily average prices

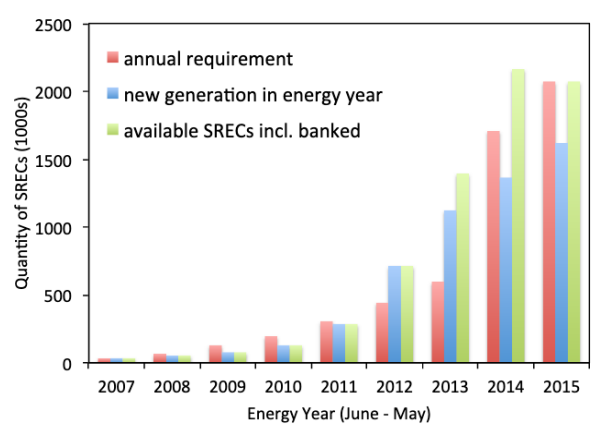

(b) Monthly SREC issuance rate

Figure 2. Historical NJ SREC prices and annual generation compared to requirement levels Source: http://energysystems.princeton.edu/Papers/Coulon\%20Khazaei\%20Powell_Mar2013.pdf. Pp. 5

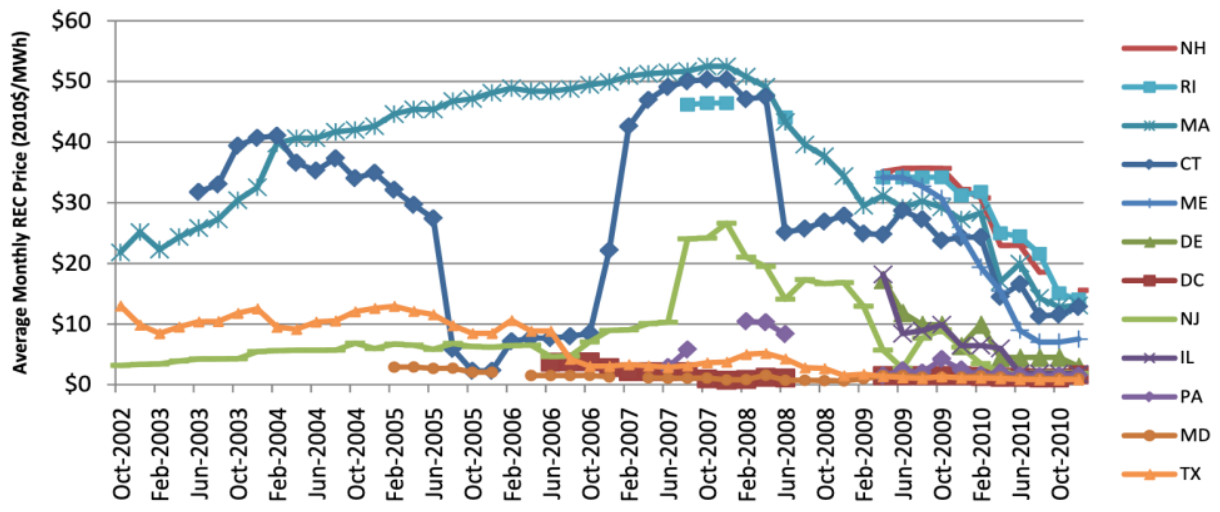

Note: Plotted values are the last trade (if available) or the mid-point of bid and offer prices for the current or nearest compliance year Source: Evolution Markets (2007) and Spectron Group (2011).

Figure 3. REC Pricing Trends Across US States, 2002-2010

Source: https://www.nrel.gov/docs/fy11osti/51904.pdf pp.11 


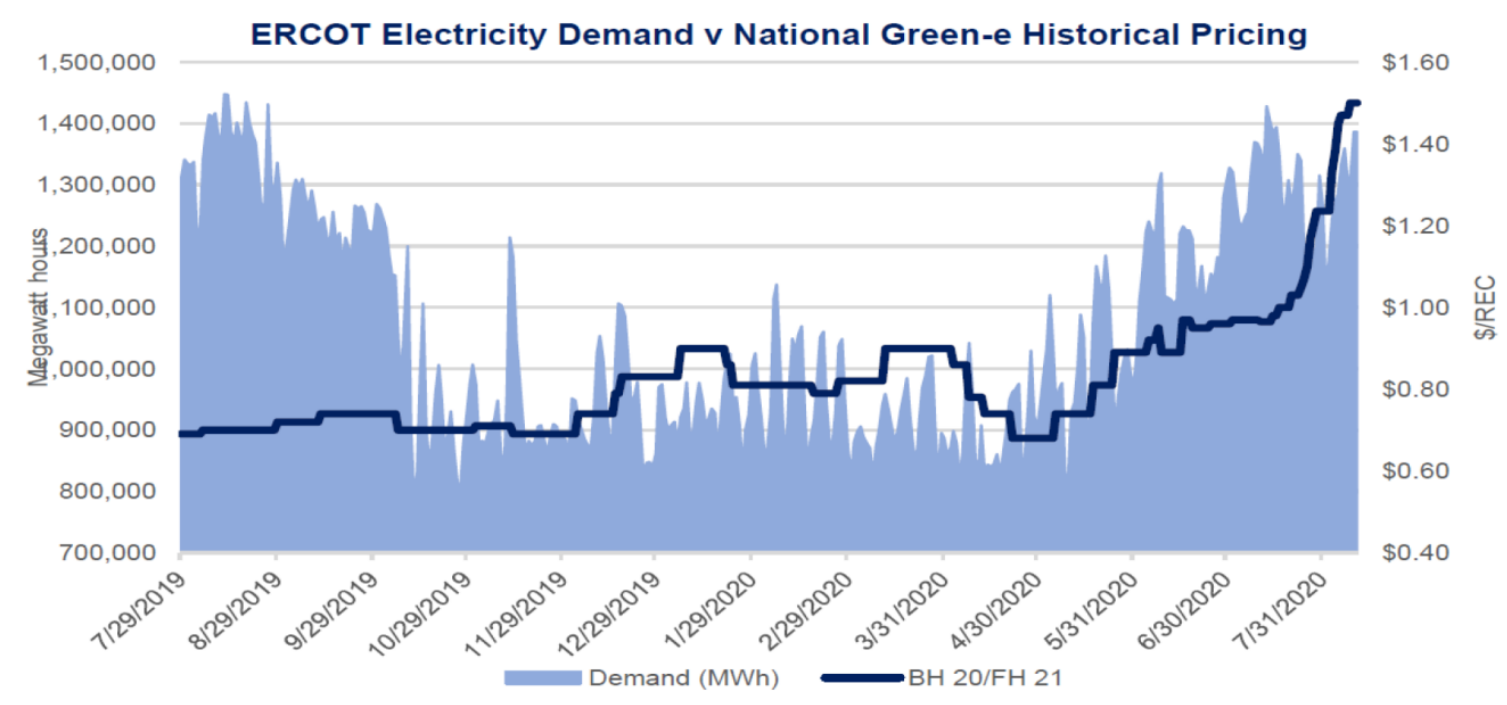

Source: Karbone (2020)

Figure 4. REC Prices vs Electricity Demand in Texas, 2019-2020

Source: Karbone 2020

Compliance markets have the most room for expansion and the most potential for economic growth due to their higher prices (Figure 2). Overall, the increase in demand is great for the green energy sector, there have been some issues in project financing for new ventures. Long-term financing is important for these projects but seems to only be plausible through the support of "large institutions or corporate buyers" that are willing to hedge price risk (Holt and Bird, 2005). Tax benefits have also been used to encourage investors in certain markets (Singh, 2011). Khazaei et al (2016) even propose a policy to help stabilize the market through collective predictive market behavior modeling. As REC markets expand, comparisons may help guide changes regarding price and market volatility (Khazaei et al, 2016). The REC market has some benefits and some downfalls, but the market is still worth investing in. The benefits include the ability to provide cost-effective green energy to a larger demographic, the reduction of transmission costs, and the ability to enable consumers to direct their money towards renewable energy if they choose. Some of the downfalls include the difficulty in marketing RECs to consumers, the inconsistency of the definition of RECs, and limited market infrastructure to track and verify the validity of RECs (Holt et al, 2011). Another major issue that concerns the expansion of RECs is how to properly regulate this complex market. A great amount of public resources and time is required to create, maintain and regulate REC markets, from generation verification, REC minting, reporting, monitoring and implementing stabilization measures.

Hulshof et al have developed performance indicators to see if the European Union energy certificate market is functioning properly (Hulshof et al, 2019). Research has found that creating international standards has a positive impact on the markets. Privatization on the other hand, can lead to more fees and lower market volume. Concluding remarks from Hulshof et al show that the EU's certification market is currently not functioning efficiently due to a lack of transparency in pricing which is also a large issue in the US markets. Market comparisons from the EU, India, and the US show patterns in volatile pricing, regulation confusion, and marketing (Holt et al, 2011).The United States government has been creating fiscal policies that positively impact the renewable energy industry. Both state and federal renewable energy tax incentives have been "the primary policy driver for the growth of wind, solar, and other renewables during the past decade" (Bhattacharyya, 2020). Tax credits have been most influential in the solar industry through the use of investment tax credit (ITC). Like RECs there are stipulations to these tax credits that prefer newer renewable energy projects over older (Bhattacharyya, 2020).

Another tax credit referred to as a production tax credit has even stricter restrictions only supporting the production of new energy builds to help boost the sector's growth. Unfortunately, Covid-19 had a large and potentially lasting impact on the growth of the industry, setting back those looking to invest in such projects (Bhattacharyya, 2020). When the 
economy is receding, tax credits are less effective as citizens and businesses do not have the extra cash to participate in voluntary programs. Economic prosperity is the best way to ensure the growth of the energy industry which can be done through strategic monetary policies. This will have a large impact on the supply of green energy and thus could push back benchmarks in areas lacking access.

On March 26th 2021, Massachusetts Gov. Charlie Baker signed a landmark climate change action bill, S.9 "An Act creating a next-generation roadmap for Massachusetts climate policy". This comprehensive and relatively aggressive legislation (compared to other US states and past bills) was developed to mitigate the wide ranging negative impacts (environmental, social and financial costs) of climate change by progressively limiting greenhouse gas (GHG) emissions from all sectors of the economy, reaching "net-zero" emissions by 2050 . Using 1990 as a base year, S9 sets firm targets of at least a $50 \%$ reduction in emissions by $2030,75 \%$ by 2040 and $85 \%$ by 2050 , with the remaining $15 \%$ achieved by natural carbon capture and storage (sequestration) through increasing vegetation, achieving net-zero emissions (Fraser, 2021). These targets are to be revisited every 5 years. S.9 builds upon the 2017 MA DEP 310 CMR 7.75: Clean Energy Standard for electricity sellers (not including Municipal Light Plants (MLPs)) which specifies an increasing minimum percentage of clean energy power supply in their portfolios, also called the Renewable Portfolio Standard (RPS). This legislation was updated by S9, so that for the first time in MA, MLPs like SELCO are included in emissions reduction requirements through a portfolio standard with carbon-free power supply sources meeting specified percentages at benchmark years up to 100\% "net-zero" in 2050 as seen on the table on page 2 and 3 of SELCO Power Supply Policy \& GGES (Attachment 1). To the researchers' knowledge, this is the first financial analysis conducted for a specific organization that is beholden to this new legislation and therefore adds unique and specific knowledge to the public policy area of utilizing RECs to meet emissions reduction goals.

\section{Methodological Approach and Discussion}

The best approach to achieving net-zero emissions differs between communities. For example, in Shrewsbury, MA, the mantra of the municipal electric utility, SELCO, has always been "low cost and reliability" with its approach to power procurement and distribution operations. Times are changing, with increased focus on environmental sustainability, both mandated by the state and voluntary interest from the community. This desire, coupled with the uncertainty of the REC markets, makes reaching a net-zero power supply sooner rather than later a prudent action. MLPs like SELCO are now stakeholders and active participants in compliance REC markets. Utilizing data, information and insight from green commodity market experts at Massachusetts Municipal Wholesale Electric Company (MMWEC, 2021), a partner of SELCO's, an economic analysis was performed on different pathways SELCO can achieve a $100 \%$ non-carbon power portfolio. This analysis was performed by Patrick Collins, using Excel. To summarize the analysis, SELCO's contracted non-carbon and potentially non-carbon MWhs (if RECs are purchased and retired rather than sold) with different generating sources for each year from 2020 (Figure 5) onwards were summed to form a baseline total non-carbon sales position (Figure 6). 


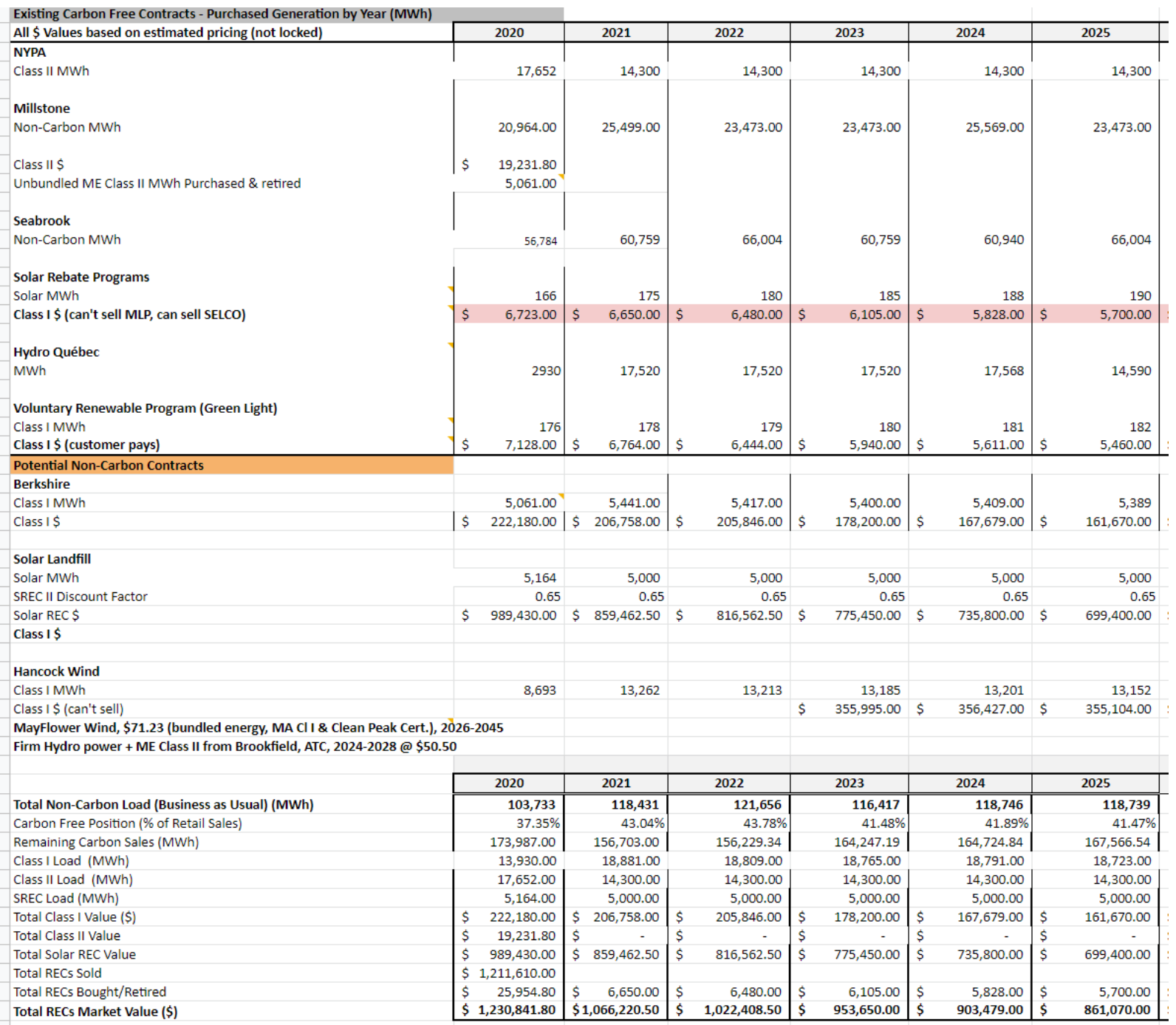

Figure 5. SELCO Existing Power Portfolio Contracts, MWhs and RECs 2020-2032

Source: Authors own calculations based on collected secondary data.

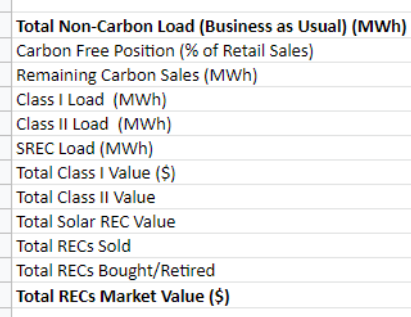

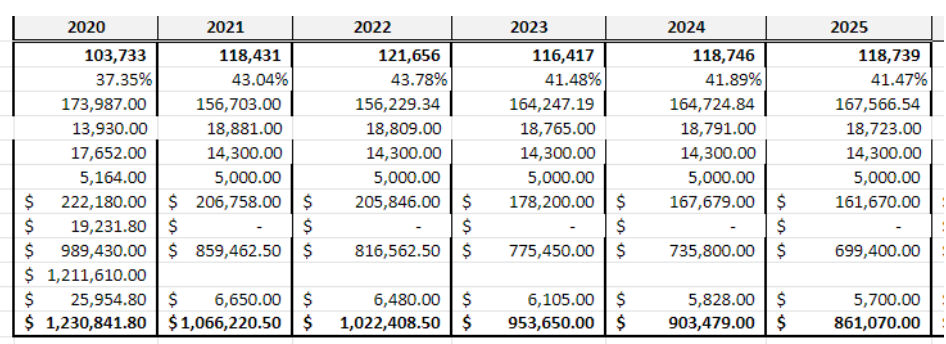

Figure 6. SELCO Existing Portfolio Summary, 2020-2032

Source: Authors own calculations based on collected secondary data.

The MWh difference between this baseline and the target non-carbon level (MWhs) based on target non-carbon portfolio percentages were multiplied with different REC prices depending on REC treatment approach, to calculate the total added cost in dollars per year (Figure 8). The revenue "lost", or opportunity cost of purchasing and retiring 
RECs rather than selling them, which SELCO has historically done, is part of this total added cost. This cost was then translated to $\$ / \mathrm{kWh}$ sold, which can be applied to customer bills. The cost to reach a net-zero, $100 \%$ non-carbon portfolio was quite low in all outlined scenarios (Figures 8, 9, 10, and 11).

One of the most important components of this analysis is how owned RECs associated with SELCO's generating assets are treated and this treatment depends on REC type or class. REC class is determined by which type of generation facility created the REC. MA Class I RECs are produced by the "cleanest" or least environmentally impactful facilities including solar and wind. These RECs have a higher value, set by the state, and are currently trading around $\$ 40$ (Figure 7). Although pricing of RECs is very difficult to predict, MMWEC experts anticipate a linear decrease to $\$ 30$ in 2025, with supply outpacing demand in initial years. This trend will likely reverse, with demand outpacing supply starting in 2026 onwards to 2032 rebounding the price back to $\sim \$ 40$ (Figure 7). MA Class II RECs are produced by lower tier facilities that have larger environmental impacts but still produce clean power, like hydro. These RECs have a lower value, set by the state, and are currently trading around \$3.80. Prices for MA Class II RECs are expected to increase to about $\$ 8$ in 2032, with a 7\% annual increase (Figure 7). Estimating REC prices has limitations and confidence in actual materialization of projections is not the best, as MMWEC experts reiterate difficulty, as the historical REC trends are volatile, do not correlate well with other indexes, markets and commodities, and are heavily influenced by public policy at the state level. For example, changes in the Alternative Compliance Payment rate set by the DOER, which acts as a price ceiling for RECs, will also likely change the expected price of RECs, as they can sometimes float just under the ACP ceiling, as seen in Figure 2a, NJ SREC prices from 2007-2011. This Figure provides an excellent example of how volatile, unpredictable and policy-influenced REC prices can be, as the prices float just under ACP for the first handful of years, then rapidly plummet in 2012, then slowly increase until 2016. The traditional economic logic of prices remaining stable with supply and demand increasing at equal rates may not apply to the REC market, with such heavy regulation. One would assume that over time, as more renewable energy projects are developed, generating more energy and RECs, increasing the clean percentage of the grid's supply, that the REC market would saturate, devalue and die. But state governments will likely set price floors and ceilings to somewhat stabilize the market and keep a value assigned to renewable energy over fossil fuels.

\begin{tabular}{|c|c|c|c|c|c|c|c|c|c|c|}
\hline REC Retirement Cost Analysis & & $\begin{array}{l}\text { Projected MWh } \\
\text { Load }\end{array}$ & $\begin{array}{l}\text { Projected } \\
\text { Change from } \\
\text { Previous Year } \\
\text { (\%) }\end{array}$ & $\begin{array}{l}\text { Projected Retail } \\
\text { Sales (MWh) }\end{array}$ & $\begin{array}{l}\text { Estimated RECs } \\
\text { Pricing-MA Class I }\end{array}$ & $\begin{array}{l}\text { Estimated 1 1ear } \\
\text { RECS Pricing- ME } \\
\text { (Class II) }\end{array}$ & $\begin{array}{l}\text { Locked 5-year RECs } \\
\text { Pricing-ME (Class II) }\end{array}$ & $\begin{array}{l}\text { Locked 10.year } \\
\text { RESC Priting-ME } \\
\text { (Class II) }\end{array}$ & $\begin{array}{l}\text { Locked } 5 \text { year RECs } \\
\text { Pricing-Class I }\end{array}$ & SRECS \\
\hline & 2020 & 287,203 & & $277,720.00$ & 40.50 & $\$ \quad 3.00$ & & & & $\$ 280.00$ \\
\hline & 2021 & 289,135 & $-0.94 \%$ & $275,134.00$ & 38.00 & 3.80 & $\$ 5.00$ & $\$ 7.60$ & $\$ 52.65$ & $\$ 264.45$ \\
\hline & 2022 & 292,026 & $-1.00 \%$ & $\begin{array}{l}277,885.34 \\
28066419\end{array}$ & 36.00 & 4.07 & $\$ 5.00$ & $\$ 7.60$ & $\$ \$ 52.65$ & $\$ 251.25$ \\
\hline & 2023 & 299,947 & $\begin{array}{l}-1.00 \% \\
-1.00 \% \\
\end{array}$ & $\begin{array}{l}280,646.19 \\
283,40.84\end{array}$ & $\begin{array}{l}33.00 \\
31.00\end{array}$ & $\begin{array}{l}4.35 \\
4.66\end{array}$ & $\$ \$ 5500$ & 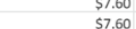 & $\$ \$ \$ 55.65$ & 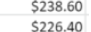 \\
\hline & 2025 & 300,875 & $\begin{array}{l}-1.00 \% \\
0.99 \%\end{array}$ & $\begin{array}{l}283,4070.84 \\
286,34\end{array}$ & $\begin{array}{l}31.00 \\
30.00\end{array}$ & $\begin{array}{l}4.66 \\
4.98\end{array}$ & $\$ 55.00$ & 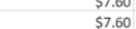 & 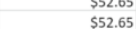 & $\$ \$ \$ 226.40$ \\
\hline & 2026 & 303,884 & $0.99 \%$ & $\begin{array}{l}280,3935.34 \\
289,168.60\end{array}$ & 36.00 & 5.33 & $\$ 5.00$ & $\$ \$ 7.60$ & 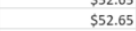 & $\$ 171.00$ \\
\hline & 2027 & 306,923 & $0.99 \%$ & $292,060.29$ & 37.00 & 5.70 & & $\$ 7.60$ & & \\
\hline & 2028 & 309,992 & $0.99 \%$ & $294,980.89$ & 38.00 & 6.10 & & $\$ 7.60$ & & $\$ 150.00$ \\
\hline & 2029 & 313,092 & $0.99 \%$ & $297,930.70$ & 39.00 & 6.53 & & $\$ 7.60$ & & $\$ 127.50$ \\
\hline & 2030 & $\begin{array}{l}316,223 \\
319385\end{array}$ & $0.99 \%$ & $300,910.00$ & 40.00 & 6.99 & & $\$ 7.60$ & & \\
\hline & 2031 & 319,385 & $\begin{array}{l}0.99 \% \\
0.99 \%\end{array}$ & $\begin{array}{l}303,919.10 \\
306,958.29\end{array}$ & 40.00 & $\begin{array}{l}7.48 \\
8.00\end{array}$ & & $\$ 7.60$ & & $\$ 92.12$ \\
\hline & 2033 & 325,805 & $0.99 \%$ & $\begin{array}{l}30,998.29 \\
310,027.88\end{array}$ & & & & & & $\$ 78.30$ \\
\hline & 2034 & 329.063 & $0.99 \%$ & $313,128.16$ & & & & & & \\
\hline & 2035 & 330,708 & $0.50 \%$ & $314,693.80$ & & & & & & \\
\hline & 2036 & 332,361 & $0.50 \%$ & $316,267.27$ & & & & & & \\
\hline & 2037 & & $0.50 \%$ & $317,848.60$ & & & & & & \\
\hline & 2038 & 335,693 & $0.50 \%$ & $319,437.85$ & & & & & & \\
\hline & 2039 & & $0.50 \%$ & $321,035.03$ & & & & & & \\
\hline & 2040 & $\begin{array}{l}339,059 \\
3440754\end{array}$ & $0.50 \%$ & $\begin{array}{l}322,640.21 \\
32425243\end{array}$ & & & & & & \\
\hline & $\begin{aligned} 2041 \\
2042\end{aligned}$ & $\begin{array}{l}\begin{array}{l}340,754 \\
342458\end{array} \\
3\end{array}$ & $0.50 \%$ & $\begin{array}{l}324,253.41 \\
325874.68\end{array}$ & & & & & & \\
\hline & $\begin{array}{l}2042 \\
2043\end{array}$ & $\begin{array}{l}\begin{array}{l}342,2588 \\
344,170\end{array} \\
3\end{array}$ & $\begin{array}{l}0.50 \% \\
0.50 \%\end{array}$ & $\begin{array}{l}325,874.68 \\
327.504 .08\end{array}$ & & & & & & \\
\hline & 2044 & 345,891 & $0.50 \%$ & $329,141.57$ & & & & & & \\
\hline & 2045 & & $0.50 \%$ & $330,787.28$ & & & & & & \\
\hline & 2046 & $\begin{array}{l}349,358 \\
3.51105\end{array}$ & $0.50 \%$ & $332,441.22$ & & & & & & \\
\hline & $\begin{array}{l}2047 \\
2048\end{array}$ & $\begin{array}{l}351,105 \\
355861\end{array}$ & $0.50 \%$ & $\begin{array}{l}334,103.42 \\
335\end{array}$ & & & & & & \\
\hline & $\begin{array}{l}2048 \\
2049\end{array}$ & $\begin{array}{l}32,861 \\
354,625\end{array}$ & $\begin{array}{l}0.50 \% \\
0.50 \%\end{array}$ & $\begin{array}{l}335,737.94 \\
337,452.81\end{array}$ & & & & & & \\
\hline & 2050 & 356,398 & $0.50 \%$ & $339,140.07$ & & & & & & \\
\hline
\end{tabular}

Figure 7. Data driving the SELCO REC Analysis, expected total electric sales and REC pricing

Source: Authors own calculations based on collected secondary data.

The most valuable RECs are produced by solar facilities (SRECs) that were constructed during the initial years of the creation of REC markets. In MA, SREC programs set very high price floors and ceilings. SELCO owns a large solar system located at the Shrewsbury landfill cap. The Solar RECs (SRECs) produced by this facility have been sold in the compliance REC markets to bring in revenue to offset the initial costs of the project. This is a common practice for most renewable energy projects and an example of the ultimate goal of RECs: to incentivize renewable energy 
development, as this project would likely not have been financially feasible without REC revenue. MA SRECs are priced extremely high, around \$280 (Figure 7). As these SREC programs are phased out by the state government, these become less valuable each year, likely dipping to below $\$ 100$ at the last available year in 2027. Because of this inflated pricing, it is best to sell SRECs and use this revenue to purchase the same MWhs (or more) with other REC types of less monetary value, such as MA Class I. In 2028, solar facilities in the SREC II program like SELCO's will produce Class I RECs going forward, instead of SRECs. Because SREC Program II was ended a few years ago, the SRECs produced are discounted from the trading price by $35 \%$, as the discount factor of 0.65 can be seen in Figure 7. It is important to note that although these different REC types have different monetary values, the contribution of MWhs to meet non-carbon power supply is the same; one SREC, one MA Class I and one MA Class II are all equal to one MWh of electric energy. The desire to purchase one over the other resides in the consumer that wants to claim certain credit for a certain environmental attribute. Locking in REC prices to reduce market fluctuation risk and exposure to volatility may also be a smart practice. 10 year and 5 year pricing is available for Class II RECs, at $\$ 7.60$ and $\$ 5$ respectively (MMWEC, 2021). The locked pricing informed the estimated 1 year pricing, as it closely matches in the last available year of each locked pricing scheme: $\$ 5.33$ vs. $\$ 5$ in 2026 and $\$ 7.48$ vs. $\$ 7.60$ in 2031 (Figure 7).

Total projected electricity retail sales (MWhs) were modelled from present day to 2050, informed by variables including historical sales, long term weather/climate forecasts and increased electrification. SELCO's sales are expected to remain stable for the next few years, around 280,000 MWhs, then increase by about $1 \%$ annually from 2024 to 2034, then $0.5 \%$ thereafter until 2050. The logic behind this is that the increased demand associated with fuel shifting the transportation sector with electric vehicles (EVs) will likely occur rapidly in the next decade or so, then plateau. Public policy and auto manufacturers are pushing towards nearly complete electrification within a decade.

SELCO's power supply portfolio was broken down between different generating sources and classified as carbon or non-carbon based on the definition set by MA legislation S.9 where RECs or EFECs must be used to count as non-carbon (Figure 5). The existing non-carbon contracts include inexpensive hydro from the New York Power Authority (NYPA) and Hydro Quebec that includes Class II REC equivalents. In 2020, hydro made up 6\% of SELCO's total power portfolio, the highest contribution from renewable power. MWhs from nuclear sources including Millstone and Seabrook are non-carbon as EFECs are associated with the purchased energy. Nuclear currently makes up the majority of SELCO's non-carbon power portfolio. In 2020, nuclear energy made up 27\% of the total power portfolio, therefore SELCO is quite reliant on nuclear power both for energy requirements and non-carbon requirements. A very small percentage of the portfolio is solar, as the SRECs from SELCO's landfill solar facility cannot be counted as non-carbon, as they are sold. The solar in the portfolio comes in the form of retirement of the MA Class I RECs produced by SELCO customers that participate in the solar rebate programs that require transfer of REC ownership to SELCO in return for a generous rebate. Another small source of MA Class I RECs in the portfolio is from SELCO's voluntary renewable program, called the Green Light Program, where SELCO customers can choose to pay a bit extra on their bills for local wind energy credit. All of these contracted MWhs add up to a baseline non-carbon position which was balanced against the total MWh sales, establishing a non-carbon percentage, which in 2020, was 37\%. There are also potential non-carbon contracts, where SELCO currently procures energy from owned renewable sources like Berkshire Wind and the Landfill Solar, where SELCO has sold these RECs for revenue; and unowned renewable sources like Hancock Wind where SELCO has opted not to purchase RECs. Treating RECs associated with these contracts differently (buying/retiring rather than selling) increases non-carbon position without having to purchase unbundled RECs on the open market.

In 2021, SELCO General Manager Chris Roy decided to continue to sell the 2020 Berkshire Class I RECs absent an official power supply policy, even though the "right" thing to do given passage of the S.9 climate bill may have been to retire the RECs and claim environmental credit. To offset the sale of these RECs and clean MWhs, Mr. Roy had SELCO purchase unbundled MA Class II RECs, the least expensive RECs in MA. This judgement-based fiscal action with regards to REC treatment to achieve emissions goals is exactly the approach that was first modelled, seen in Figure 8, "Sell all RECs, buy Cl II, w/ est. 1 yr prices". In this scenario, the revenue from the sale of more valuable MA Class I RECs that SELCO can bring in is used to purchase less valuable Class II RECs but a greater number, therefore reaching $100 \%$ in 2030.

Another fiscal policy approach that was modelled is titled "Buy REC in contracts, Buy Cl I for Solar, Buy Cl II, w/ est. 1 yr prices" as seen in Figure 8, where all contractual RECs are bought and retired, rather than sold on the market, except for SRECs, which are always sold and replaced with Class I, and any remaining difference needed to reach a given year's target non-carbon percentage goal is made up with Class II RECs. This same REC treatment approach was modelled with locked pricing as well. The target year for $100 \%$ non-carbon was set at 2032, with 5\% annual increase from $45 \%$ at 2021. The last approach that was modelled uses this same REC treatment, but reaches $100 \%$ at the last 
possible year in 2050, with a $2 \%$ annual increase from $43 \%$ in 2021. Costs were not modelled past 2032 due to higher uncertainty about REC pricing and state policy. Things are changing so rapidly in this area that it could be a whole new world in the later years.

Limitations of this analysis include the difficulty of predictive REC market modelling, as mentioned several times, as well as the fact that new contracts are not considered. Without doubt, SELCO will enter into new long-term contracts that provide bundled non-carbon energy and environmental attributes such as Mayflower Wind and local hydro like Brookfield, both before 2030 and likely lasting decades. MMWEC has advised that off-shore wind like Mayflower should contribute at least 10\% of SELCO's power supply, as it is relatively low cost Class I renewable energy and more reliable than on-shore wind and solar. It can also provide Clean Peak Certificates, which will be a new environmental attribute associated with large scale projects that can provide essential power during peak demand events. All inclusive, bundled long term contracts like this can substantially reduce the cost of meeting emissions reduction targets, therefore this analysis may overestimate costs to net-zero emissions.

\section{Research Findings}

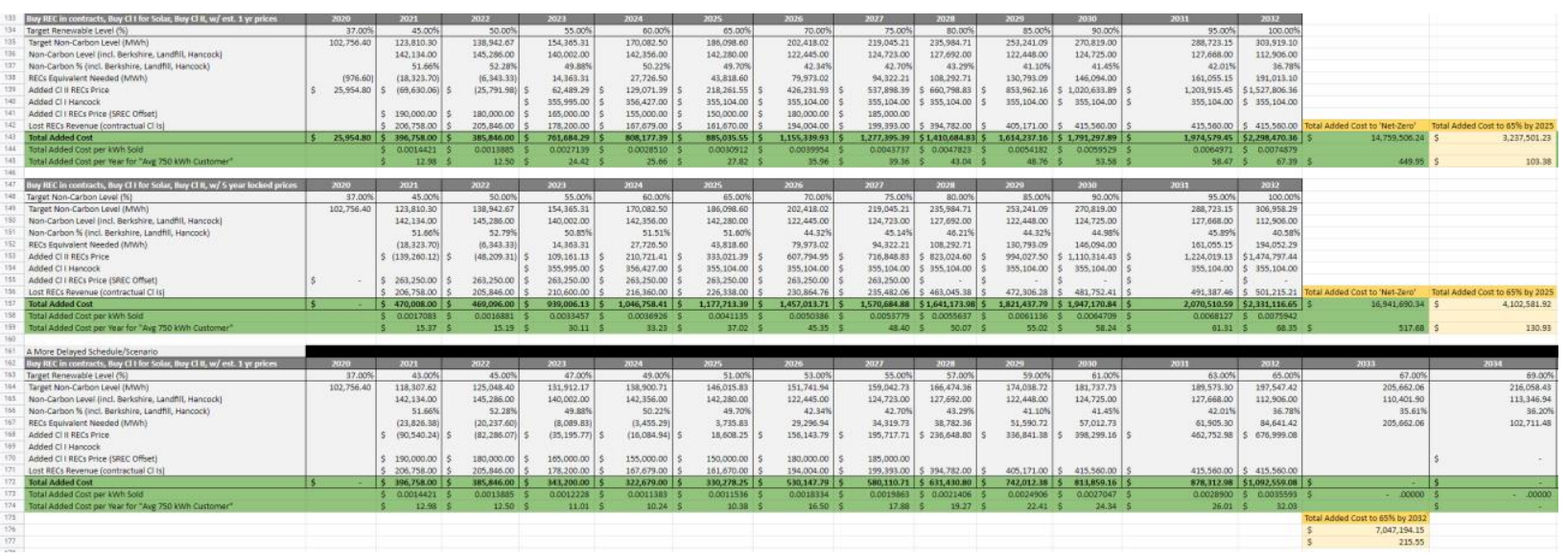

Figure 8. Different approaches to $100 \%$ non-carbon power supply 'net-zero'

Source: Authors own calculations based on collected secondary data.

As seen in Figure 8, the financial cost to reach $100 \%$ non-carbon power supply utilizing RECs is quite low, making this endeavor affordable for public electric utilities like SELCO. Millions of dollars might seem like a lot of money, but spread over thousands of customers on a $\mathrm{kWh}$ basis, over a decade, the costs per bill is minimal; some would say unnoticeable. This aligns with the costs that other MA MLPs incurred that have power portfolios that are at or very close to $100 \%$ non-carbon, like Concord Light and Belmont Light. The modelled total cost to $100 \%$ net-zero emissions with the cheapest REC treatment approach "Sell all RECs, buy Cl II" while hitting 100\% early in 2030, is $\$ 5,821,961.34$ (Figure 8, row 129). The total added cost of purchasing unbundled Class II REC on the market increases each year, starting at $\$ 19,764.94$ in 2021 and $\$ 1,373,000.38$ in 2030. With estimated 1 year pricing, the total cost of the for the more balanced REC treatment approach, where contractual RECs are purchased and retired for credit, except for solar, and the needed difference to meet target non-carbon percentage is made up with Class II NEPOOL (New England Region) RECs, is $\$ 14,759,506.24$, hitting net-zero in 2032 (Figure 8, row 143). The total added cost of purchasing increases each year, starting at $\$ 396,758.00$ in 2021 due to the lost revenue from not selling the contracted Class I RECs and purchasing Class I RECs to offset SRECs selling. This REC treatment approach boosts SELCO's baseline non-carbon percentage because RECs from contracts including Berkshire, Hancock and the Landfill Solar are counted for credit. This hovers around and over 50\% non-carbon between 2021 and 2025, then dips in later years due to contracted MWhs decreasing (Figure 8). This approach actually puts the portfolio ahead of targeted non-carbon levels in the first couple of years, seen in the negative "RECs Equivalent Needed (MWh)" in Figure 8. The added cost per $\mathrm{kWh}$ starts at around 1/10th of one cent $(\$ 0.0014421)$ and increases to just over 7/10th of one cent $(\$ 0.0074879)$ in 2032 (Figure 8). Translating this per $\mathrm{kWh}$ cost to the average residential customer that uses $750 \mathrm{kWh}$ a month on average, it would cost around $\$ 13$ per year, or a bit over $\$ 1$ per month, in 2021 . This cost increases to $\$ 67.39$ per year 
in 2032, or a bit under $\$ 6$ per month (Figure 8). Adding the per kWh cost to the average $750 \mathrm{kWh}$ customer's bill, would lead to a total electric bill of $\$ 96.99$ in 2032 with a $100 \%$ non-carbon power supply, less than a $\$ 6$ difference from the current $\$ 91.37$ based on SELCO's current residential rate of $\$ 0.11516$ per kWh (Figure 9).

\begin{tabular}{|c|c|c|c|c|c|c|c|c|c|c|c|c|}
\hline Year & 2021 & 2022 & 2023 & 2024 & 2025 & 2026 & 2027 & 2028 & 2029 & 2030 & 2031 & 2032 \\
\hline Carbon Free \% & $45 \%$ & $50 \%$ & $55 \%$ & $60 \%$ & $65 \%$ & $70 \%$ & $75 \%$ & $80 \%$ & $85 \%$ & $90 \%$ & $95 \%$ & $100 \%$ \\
\hline Rate per kWh (2021 Baseline) & $\$ 0.11516$ & $\$ 0.11516$ & $\$ 0.11516$ & $\$ 0.11516$ & $\$ 0.11516$ & $\$ 0.11516$ & $\$ 0.11516$ & $\$ 0.11516$ & $\$ 0.11516$ & $\$ 0.11516$ & $\$ 0.11516$ & $\$ 0.11516$ \\
\hline Added kWh Cost & $\$ 0.00144$ & $\$ 0.00139$ & $\$ 0.00271$ & $\$ 0.00285$ & $\$ 0.00309$ & $\$ 0.00400$ & $\$ 0.00437$ & $\$ 0.00478$ & $\$ 0.00542$ & $\$ 0.00595$ & $\$ 0.00650$ & $\$ 0.00749$ \\
\hline Average Montly kWh Usage & 750 & 750 & 750 & 750 & 750 & 750 & 750 & 750 & 750 & 750 & 750 & 750 \\
\hline Customer Charge & $\$ 5.00$ & $\$ 5.00$ & $\$ 5.00$ & $\$ 5.00$ & $\$ 5.00$ & $\$ 5.00$ & $\$ 5.00$ & $\$ 5.00$ & $\$ 5.00$ & $\$ 5.00$ & $\$ 5.00$ & $\$ 5.00$ \\
\hline Montly Cost (2021 Baseline) & $\$ 91.37$ & $\$ 91.37$ & $\$ 91.37$ & $\$ 91.37$ & $\$ 91.37$ & $\$ 91.37$ & $\$ 91.37$ & $\$ 91.37$ & $\$ 91.37$ & $\$ 91.37$ & $\$ 91.37$ & $\$ 91.37$ \\
\hline Added Monthly REC Cost & $\$ 1.08$ & $\$ 1.04$ & $\$ 2.04$ & $\$ 2.14$ & $\$ 2.32$ & $\$ 3.00$ & $\$ 3.28$ & $\$ 3.59$ & $\$ 4.06$ & $\$ 4.46$ & $\$ 4.87$ & $\$ 5.62$ \\
\hline Total Monthly Bill & $\$ 92.45$ & $\$ 92.41$ & $\$ 93.41$ & $\$ 93.51$ & $\$ 93.69$ & $\$ 94.37$ & $\$ 94.65$ & $\$ 94.96$ & $\$ 95.43$ & $\$ 95.83$ & $\$ 96.24$ & $\$ 96.99$ \\
\hline Added Yearly REC Cost & $\$ 12.98$ & $\$ 12.50$ & $\$ 24.43$ & $\$ 25.66$ & $\$ 27.82$ & $\$ 35.96$ & $\$ 39.36$ & $\$ 43.04$ & $\$ 48.76$ & $\$ 53.58$ & $\$ 58.47$ & $\$ 67.39$ \\
\hline Total Annual Bill & $\$ 1,062.40$ & $\$ 1,061.43$ & $\$ 1,085.29$ & $\$ 1,087.76$ & $\$ 1,092.08$ & $\$ 1,108.36$ & $\$ 1,115.17$ & $\$ 1,122.52$ & $\$ 1,133.97$ & $\$ 1,143.59$ & $\$ 1,153.39$ & $\$ 1,171.22$ \\
\hline
\end{tabular}

Figure 9. Modelled costs for the recommended approach for the typical $750 \mathrm{kWh} /$ month customer

Source: Authors own calculations based on collected secondary data.

\section{COST COMPARISON PER 750kWh as of uur 1,2021}

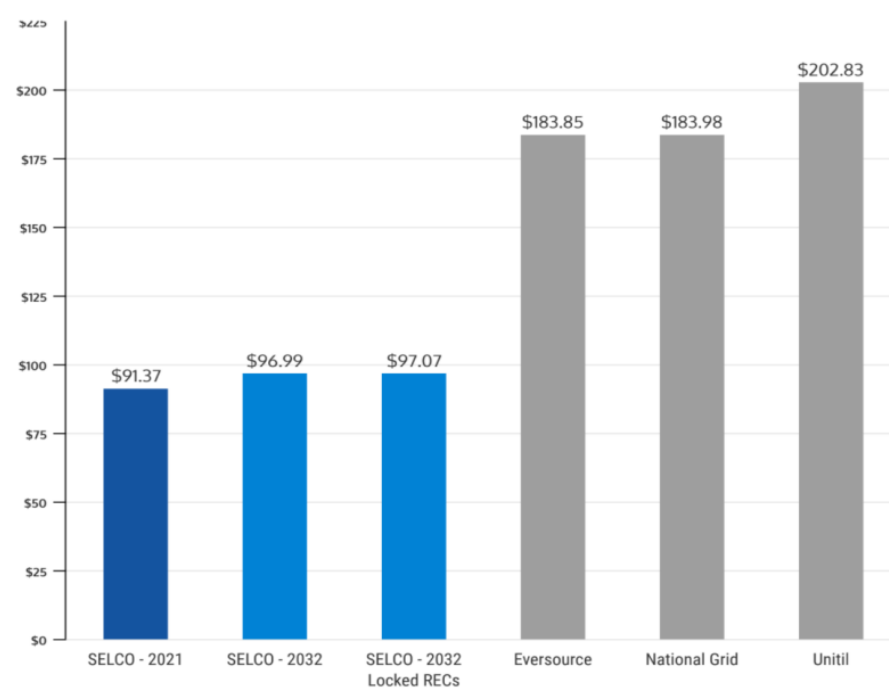

SELCO's estimated 2032 100\% Net-Zero rate would be approximately half as much as neighboring IOU $\mathbf{Q} \mathbf{1 2 0 2 1}$ rates for $750 \mathrm{kWh}$ of residential use.

Tracking projected future REC market fluctuations, we estimate the 2032 cost per 750kWh will be $\$ 96.99$ per month.

If the Commimssion prefers to stablize the impact of possible future REC market fluctuations, locked REC pricing is available. Under that model, the 2032 montly cost for $750 \mathrm{kWh}$ will be $\$ 97.07$.

Figure 10. SELCO modelled costs vs Investor owned Utilities 


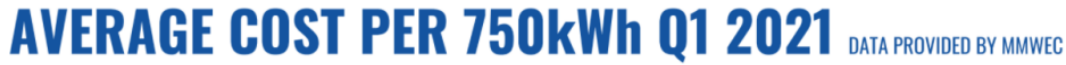

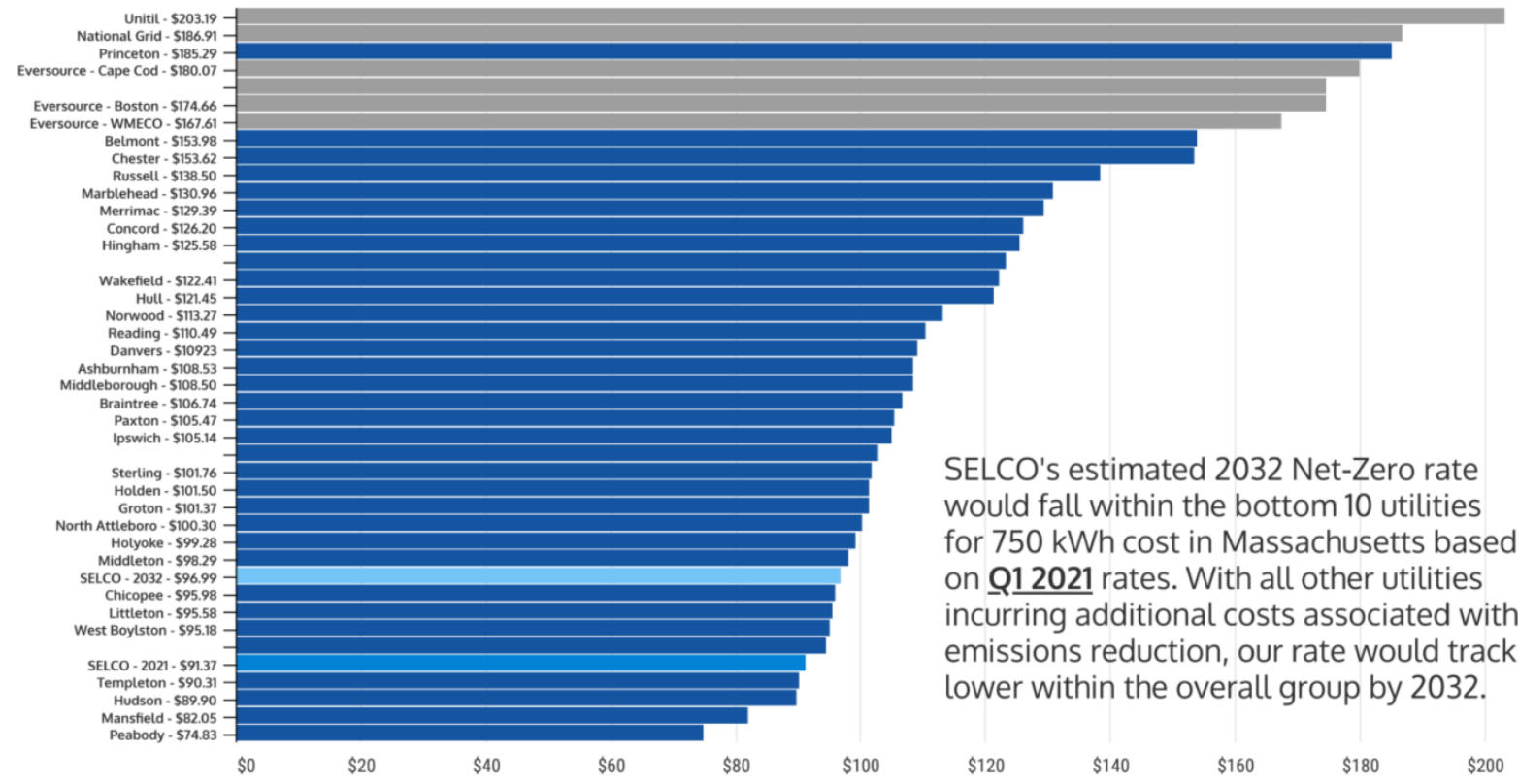

Figure 11. SELCO net-zero modelled costs, SELCO current costs, compared to other public and private utilities

Source: Authors own calculations based on collected secondary data.

These expected bills are still around half of what investor owned utilities (IOUs) like National Grid and Eversource currently charge their customers, as seen in Figure 10 and Figure 11. Electric customers serviced by MLPs like SELCO are lucky in this regard to have such great service at a low cost, from both financial and environmental viewpoints. Cumulatively, from 2021 to 2032, this average customer would pay a total of about $\$ 450$ (Figure 8).

In the more delayed schedule, where $100 \%$ is reached in 2050 , the last possible year to meet that requirement, a $65 \%$ non-carbon is reached in 2032 . The total added cost of reaching $65 \%$ is $\$ 7,047,194.15$, or $\$ 215.55$ per "average 750 $\mathrm{kWh}$ customer" over this time period of 11 years (Figure 8). Comparing this to the more aggressive approach, the total cost of achieving the same $65 \%$ non-carbon level earlier in 2025 is less than half, at $\$ 103.38$ per average $750 \mathrm{kWh}$ customer over those 5 years. The slight decrease in total annual cost in all scenarios from 2021 to 2022 is due to the slight increase in baseline non-carbon percentage from contracted MWhs increasing as well as the expected decrease in pricing for MA Class I RECs. Again, all of these modelled costs to achieve $100 \%$ non-carbon power supply align with historical actual costs that other MLPs have incurred, which is reassuring to the validity of this model.

\section{Policy Recommendation and Conclusions}

Rules-based and judgement-based fiscal policy should be adopted by SELCO to create a formal power supply policy and greenhouse gas emissions standard (GGES) based on the findings of this analysis. A diverse, layered and staggered approach to both energy and environmental attribute procurement should be taken, where reliance on one contract should not exceed $20 \%$ of the total portfolio. The complete policy document can be seen in the Attachment section. Considering the uncertainty of REC markets beyond $~ 2032$, increased demand, the potentially limited supply of RECs, increasing prices, and the results of the financial analysis of the modelled costs to reach $100 \%$ non-carbon power supply, the best approach to reaching this emissions reduction goal is to participate proactively in this market and procure RECs well ahead of minimum schedule requirements, while still retaining low electric rates and excellent reliability. It is recommended that $100 \%$ is reached in 2032, increasing 5\% annually from $45 \%$ in 2021 . The target non-carbon level is rules based policy, where these levels must be met.

Because there is more price stability in bundled energy and REC contracts, and because it is easier for the general public to understand, it is recommended that SELCO take the REC treatment approach of purchasing and retiring RECs associated in all available power purchase contracts. The only exception to this would be SRECs from SELCO's 
solar facility where they should be sold for the expected revenue that was relied on for project feasibility, but some of this revenue should be used to purchase the equivalent MWhs in Class I RECs. This REC treatment approach is rules-based fiscal policy, where RECs must be treated in this way. Judgement based fiscal policy comes into play in the "Periodic Review" section of the policy document, where SELCO should revisit this policy given REC market conditions and re-run financial models to compare predicted costs versus actual costs. It is recommended that this periodic review be conducted at least annually, but not more than quarterly. It is also recommended that SELCO reconsider the format of their voluntary green pricing program, Green Light, as it may not be necessary as the portfolio increases in its non-carbon position. When at 100\% non-carbon in 2032, all of the electricity in Shrewsbury can be claimed as clean energy and all customers will be paying slightly higher bills instead of a select few. The program could be modified so that customers can choose to pay extra for a higher REC class or a specific type of renewable (e.g., local solar).

This extensive and unique analysis of the financial options to reach $100 \%$ clean power for a public utility fills some of the holes that previous research has left open for research. Utilizing REC markets to achieve emissions reduction goals and requirements is possible, and is not that expensive in this case. Limitations of this analysis include the difficulty of predictive REC pricing, due to market volatility and dependence on state legislation and oversight, as well as the fact that new contracts are not considered. Further research is needed to develop a more robust predictive model of the future of the REC market. It is recommended that SELCO should also stay tuned to the public policy debates in this area, especially related to any potential updates, changes and restructuring of renewable energy monetary policy and mechanisms. REC markets have the strength of incentivizing the development and use of renewable, clean energy instead of fossil fuels, but have drawbacks such as difficulty in marketing these products, volatile prices, inconsistent definitions and processes between states. Uncertainty about the impact of public policy in the late years approaching 2035 and beyond makes long-term market predictions nearly impossible, but one could argue that is the case with many other markets. The current setup where states create markets for and assign value to environmental attributes produced by certified clean generating sources is proven to work effectively and likely to stick around for a while, perhaps in perpetuity, but there is always potential for new monetary systems to be created to incentivize renewable energy over fossil fuels.

\section{References}

Bhattacharyya, B. (2020, May 28). Renewable energy tax credits: The case for refundability. Center for American Progress. Retrieved from https://www.americanprogress.org/issues/green/reports/2020/05/28/485411/renewable-energy-tax-credits-case-r efundability/

Environmental Protection Agency. Renewable Energy Certificates EPA. Retrieved from https://www.epa.gov/greenpower/renewable-energy-certificates-recs

Fraser, D. (2021, April 3). Massachusetts new climate change BILL 'worth WAITING FOR'. Retrieved April 1, 2021, from https://www.capecodtimes.com/story/news/2021/03/31/new-ma-climate-change-bill-worth-wait/7060370002/

Heeter, J., \& O'Shaughnessy, E. (2020, September). Status and Trends in the Voluntary Market (2019 data). Renewable Energy Markets Conference. Virtual.

Holt, E., \& Bird, L. (2005, January). Emerging Markets for Renewable Energy Certificates: Opportunities and Challenges. United States. https://doi.org/10.2172/15011466

Holt, E., Sumner, J., \& Bird, L. (2011, June). Role of Renewable Energy Certificates in Developing New Renewable Energy Projects. United States. https://doi.org/10.2172/1018490

Hulshof, D., Jepma, C., \& Mulder, M. (2019, May). Performance of markets for European renewable energy certificates. Energy Policy, 128, 697-710. https://doi.org/10.1016/j.enpol.2019.01.051

Khazaei, J., Coulon, M., \& Powell, W. B. (2017). Adapt: A price-stabilizing compliance policy for renewable energy certificates: The case of SREC markets. Operations Research, 65(6), 1429-1445. https://doi.org/10.1287/opre.2017.1641

MMWEC (Massachusetts Municipal Wholesale Electric Company). (2021). Market expert insight in oral and written form. Loading and price data. 
Singh, A. (2011). Directions for Effective Regulation for Renewable Energy: An Analysis of Renewable Energy Certificates. India Energy Security Summit: Energy Security for a sustainable future, 3-4. https://doi.org/10.2139/ssrn.3440341

U.S. Department of Energy. Renewable energy credits (recs). Energy Sage. Retrieved from https://www.energysage.com/other-clean-options/renewable-energy-credits-recs/

Wang, G., Zhang, Q., Li, Y., Mclellan, B. C., \& Pan, X-Z. (2019). Corrective regulations on renewable energy certificates trading: Pursuing an equity-efficiency trade-off. Energy Economics, 80, 970-982. https://doi.org/10.1016/j.eneco.2019.03.008

\section{Copyrights}

Copyright for this article is retained by the author(s), with first publication rights granted to the journal.

This is an open-access article distributed under the terms and conditions of the Creative Commons Attribution license (http://creativecommons.org/licenses/by/4.0/). 